\section{Acute lung injury}

\author{
Dhruv Parekh, research fellow; Rachel C \\ Dancer, clinical lecturer; David R Thickett, \\ reader in respiratory medicine
}

Centre for Translational Inflammation

Research, School of Clinical and

Experimental Medicine, University of

Birmingham

Acute lung injury (ALI) and the more severe acute respiratory distress syndrome (ARDS) are the pulmonary manifestations of an acute systemic inflammatory process characterised clinically by pulmonary infiltrates, hypoxaemia and oedema. It occurs predominantly in young, previously healthy people, and is responsible for thousands of adult and paediatric deaths annually worldwide. Both ALI and ARDS confer a considerable long-term illness and disability burden on the individual sufferer and on society.

\section{Historical background}

In 1967 Ashbaugh et al published the first description of 12 patients with similar clinical, physiological, radiographic and pathology findings, later described as ARDS. ${ }^{1}$ These patients had acute respiratory distress, cyanosis refractory to oxygen therapy, decreased lung compliance and diffuse pulmonary infiltrates on chest $\mathrm{X}$-ray. It is, however, clear that patients with ARDS had been described before, particularly in the context of battlefield trauma. Thus, post-traumatic lung injury has been described as 'wet lung' in World War II, 'shock lung' or 'Da-Nang lung' after a bloody battle during the Vietnam War.

\section{Definitions}

ALI and ARDS are clinical syndromes characterised by the acute onset ( $<7$ days) of severe hypoxaemia and bilateral pulmonary infiltrates in the absence of clinical evidence of left atrial hypertension. The severity of the hypoxaemia differentiates ALI from ARDS. The American/European Consensus Conference defined patients as having ALI or ARDS according to the ratio of partial pressure of oxygen in arterial blood $\left(\mathrm{PaO}_{2}\right)$ to the inspired fraction of oxygen $\left(\mathrm{FiO}_{2}\right.$ ) being less than 300 (ALI) or less than 200 (ARDS) (Table 1). ${ }^{2}$

\section{Incidence}

The overall incidence of ARDS remains unclear, but most studies suggest approximately $2-8$ cases per 100,000 population per year. ALI is more common, with rates up to 25 per 100,000 per year reported. Epidemiologic investigations of both have predominantly focused on mechanically ventilated patients in intensive care units (ICU), but recent data suggest about $9 \%$ of patients in respiratory isolation wards meet the criteria for ALI at some point during their admission. Patients managed on the wards only had a much better prognosis than those who have to be managed in ICU. ${ }^{3}$

\section{Clinical risk factors for acute lung injury}

Certain known risk factors such as sepsis, trauma or multiple traumatic injuries may lead to the development of ALI and ARDS. The mode of lung injury can be either direct or remote to the lung. A list of common causes is shown in Table 2. However, only a relatively small proportion of patients with risk factors actually develop ALI, research suggesting that genetic, demographic (age), social (smoking, alcohol abuse) and other factors play a role in determining who develops ALI. ${ }^{4,5}$

Table 1. The diagnostic criteria for acute lung injury (ALI).

ALI and ARDS are defined as:

1 Acute onset

2 Bilateral pulmonary infiltrates on chest x-ray

3 Pulmonary capillary wedge pressure $<18 \mathrm{mmHg}(2.4 \mathrm{kPa}$ ) or absence of left atrial hypertension clinically

$4 \mathrm{PaO}_{2} / \mathrm{FiO}_{2}{ }^{*}<300 \mathrm{mmHg}(40 \mathrm{kPa})=\mathrm{ALI}$

$5 \mathrm{PaO}_{2} / \mathrm{FiO}_{2}<200 \mathrm{mmHg}(26.7 \mathrm{kPa})=$ ARDS

ARDS = acute respiratory distress syndrome.
In patients in hospital with septic shock, ALI is associated with delayed goaldirected resuscitation, delayed antibiotics, transfusion, alcohol abuse, recent chemotherapy, diabetes mellitus and baseline respiratory rate. ${ }^{6}$ As discussed earlier, onset of ALI/ARDS is acute, with a diagnosis being made after a median of one day after hospital admission. Patients who develop ALI/ARDS with pulmonary conditions generally do so more quickly than extrapulmonary patients.

\section{Pathophysiology}

ALI is characterised by neutrophil recruitment to the lung, with both alveolar and systemic release of chemokines (eg CXCL-8, ENA-78), pro-inflammatory cytokines (eg interleukin (IL)-1, IL-6, tumour necrosis factor), acute-phase reactants (eg C-reactive protein, lipocalin), and matrix remodelling enzymes (eg MMP-9). Exaggerated neutrophilic inflammation is believed to damage the alveolar-capillary barrier, ${ }^{7-9}$ leading to the development of non-cardiogenic pulmonary oedema which impairs gas exchange, causing the need for mechanical ventilation (Fig 1a). The subsequent course of ARDS is variable. In some patients there is reabsorption of alveolar oedema fluid and repair of the injured region of the alveolar epithelium, followed by clinical recovery from respiratory failure (Fig 1b). In other patients alveolar oedema persists, followed

Table 2. Conditions associated with the development of acute lung injury.

\begin{tabular}{|c|c|}
\hline \multicolumn{2}{|c|}{ Lung injury } \\
\hline Remote & Direct \\
\hline Sepsis & Pneumonia \\
\hline Multiple trauma & $\begin{array}{l}\text { Aspiration of } \\
\text { gastric contents }\end{array}$ \\
\hline $\begin{array}{l}\text { Cardiopulmonary } \\
\text { bypass }\end{array}$ & Swine flu \\
\hline Post-oesophagectomy & Near drowning \\
\hline $\begin{array}{l}\text { Acute pancreatitis } \\
\text { inhalation }\end{array}$ & Smoke \\
\hline \multirow[t]{2}{*}{$\begin{array}{l}\text { Massive blood } \\
\text { transfusion }\end{array}$} & $\begin{array}{l}\text { Pulmonary } \\
\text { contusion }\end{array}$ \\
\hline & $\begin{array}{l}\text { Post lung } \\
\text { transplantation }\end{array}$ \\
\hline
\end{tabular}



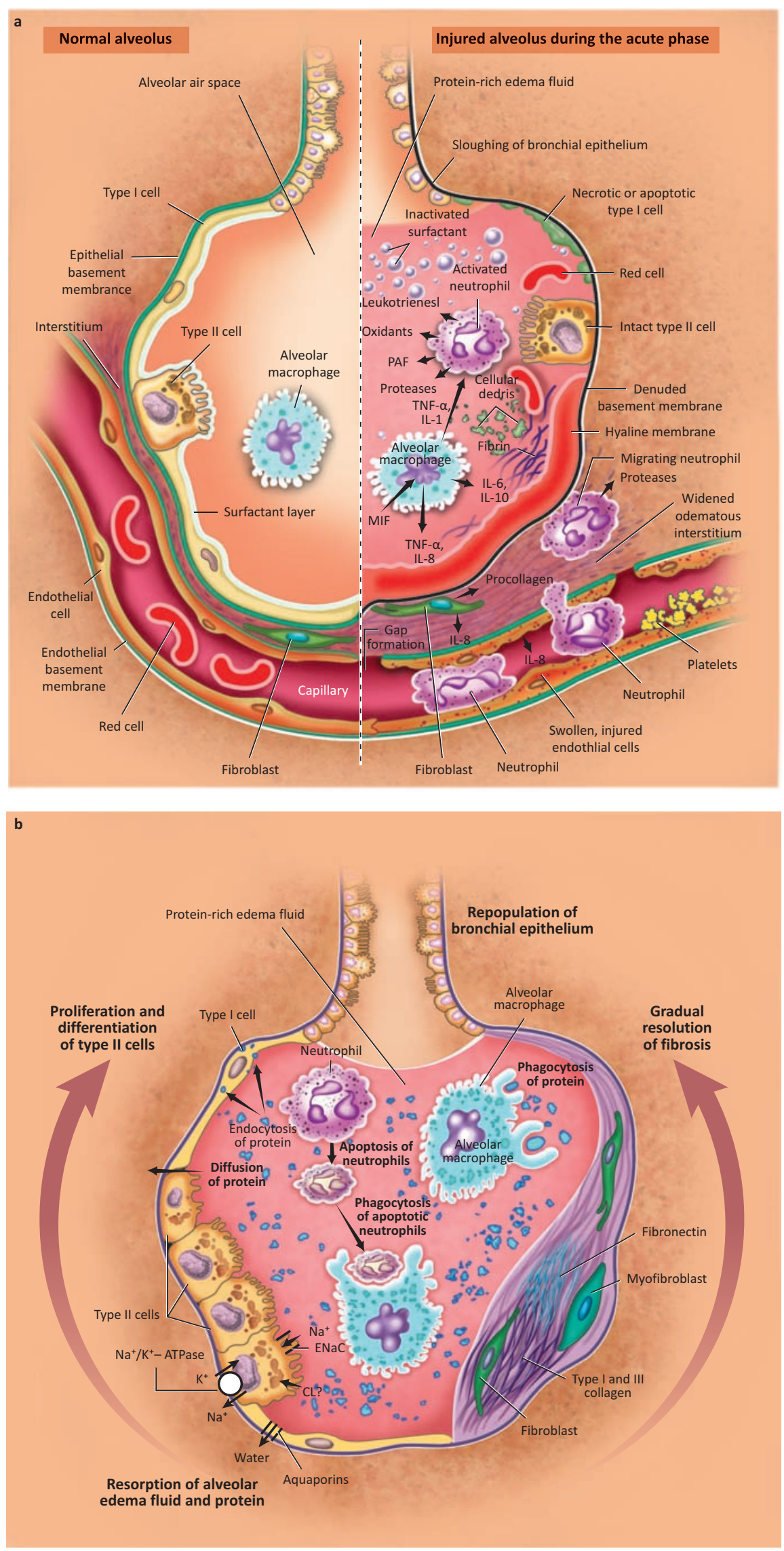

by organisation of hyaline membranes and gradual appearance of intra-alveolar fibrosis and scarring. ${ }^{5}$

\section{Clinical evaluation}

Clinical features suggestive of ALI are severe dyspnoea, tachypnoea, and resistant hypoxaemia plus the clinical features of the initiating injury (eg bowel perforation and sepsis syndrome). All patients should be assessed for an underlying cause (particularly pneumonia, sepsis, pancreatitis or transfusion related lung injury) and treated promptly. Rigorous examination is required to look for occult sources of sepsis such as deep soft tissue infections, and appropriate diagnostic tests (eg blood/urine cultures, bronchoalveolar lavage) performed. If no underlying diagnosis is found, invasive lung biopsy is appropriate to rule out conditions such as diffuse alveolar haemorrhage that may respond to immunosuppression. ${ }^{10}$

\section{Initial management of cases}

There is no current licensed therapeutic treatment for ALI per se. Critical care support is usually required and treatment of the underlying condition to remove the underlying initiating stimulus for the injury.

\section{Protective ventilation}

The ARDSnet trial of lung protective ventilation strategy compared a control ventilatory strategy with a tidal volume $\left(\mathrm{V}_{\mathrm{t}}\right)$ of $12 \mathrm{ml} / \mathrm{kg}$ (based on predicted body weight $(\mathrm{PBW})$ ) to a lung protective strategy using a $\mathrm{V}_{\mathrm{t}}$ of $6 \mathrm{ml} / \mathrm{kg}$ PBW. ${ }^{11}$ The study was stopped early when an interim analysis revealed that the mortality rate in the lung protective group was $22 \%$ lower than in the

Fig 1. (a) The normal alveolus (left) and the injured alveolus (right) in the acute phase of acute lung injury (ALI) and the acute respiratory distress syndrome (ARDS); (b) mechanisms important in the resolution of ALI and ARDS. ATPase $=$ adenosine triphosphatase; $\mathrm{ENaC}=$ epithelial sodium channel; IL = interleukin; $\mathrm{MIF}=$ macrophage inhibitory factor; PAF = platelet activating factor; TNF = tumour necrosis factor. Reproduced with permission from the New England Journal of Medicine. ${ }^{9}$ 
Table 3. Failed therapies for acute lung injury/acute respiratory distress syndrome (ARDS).

\begin{tabular}{lll}
$\begin{array}{l}\text { Trial } \\
\text { KARMA }\end{array}$ & Therapy \\
$\begin{array}{l}(n=234) \\
\text { LaSRS }^{16} \\
(n=180)\end{array}$ & Ketoconazole & Outcome \\
$\begin{array}{l}\text { LARMA } \\
(n=235)\end{array}$ & Methylprednisolone for late-phase ARDS & Stopped early due to lack of efficacy \\
$\begin{array}{l}\text { ALTA } \\
(n=282)\end{array}$ & Lisofylline & No mortality benefit \\
$\begin{array}{l}\text { BALTI-2 } \\
(n=250)\end{array}$ & Nebulised salbutamol & Stopped early due to lack of efficacy \\
\hline iv $=$ intravenous. & iv salbutamol & Stopped early due to lack of efficacy \\
\end{tabular}

control group. These beneficial results seemed to hold across a wide spectrum of patients, including septic and non-septic patients, and also those with different degrees of lung dysfunction as assessed by respiratory system compliances. A lung protective ventilation strategy should therefore be initiated for all cases of ALI.

\section{Fluid management}

Another advance in supportive therapy was recently reported by the National Heart, Lung and Blood Institute ARDS Network with the results of a prospective, randomised clinical trial evaluating the use of a liberal versus conservative fluid strategy in patients with ALI. ${ }^{12}$ The latter resulted in a significant increase in ventilator-free days and a nonsignificant decrease in mortality (3\%). The conservative fluid management strategy used diuretics to target a central venous pressure less than $4 \mathrm{mmHg}$ or a pulmonary artery occlusion pressure below $8 \mathrm{mmHg}$.

\section{Non-conventional ventilation}

Non-conventional methods of ventilation, including high frequency ventilation and liquid ventilation, have not so far proven effective. An alternative modality, high frequency oscillation ventilation (HFOV), is increasingly used in some centres. Although its use other than as a salvage treatment remains debatable, a recent updated meta-analysis suggests that it improves oxygenation, risk of treatment failure and 30-day mortality compared with conventional ventilation. ${ }^{13}$ Ongoing phase 3 studies of HFOV versus a conven- tional lung protective ventilation strategy are due to report next year and should provide definitive answers about its efficacy. In contrast, efficacy studies of liquid ventilation have been disappointing and its optimal clinical use has yet to be defined.

Extracorporeal membrane oxygenation (ECMO) has been studied in a UK trial (CESAR) of 180 patients with refractory hypoxaemia. Patients were randomised to transfer to a tertiary care centre where $77 \%$ received ECMO or to remain at the referring centre and be treated with non-protocolised ventilator strategies. Compared with the control group, transferring adult patients with severe but potentially reversible respiratory failure to a single centre specialising in the treatment of severe respiratory failure for consideration of ECMO significantly increased survival without severe disability. ${ }^{14}$ Considerable debate is ongoing as to whether this trial proves the benefit of ECMO per se or the benefits of managing severe respiratory failure in specialist centres of excellence.

\section{Failed pharmacological therapies for acute lung injury}

Numerous pharmacological therapies for established ALI have failed to show benefit in multicentre clinical trials (examples given in Table 3). Despite corticosteroids being the most studied drugs for ALI, overall current evidence to support their use for treating early or late ALI is limited because of concern about increased neuromyopathic events with no mortality benefit. ${ }^{16}$ Nevertheless, a subsequent trial with lowdose corticosteroids in early ARDS reported significant improvement in hypoxaemia and lung injury scores as early as days 1 and $2 .{ }^{18}$

There remain uncertainties and conflicting evidence that still need answers from an adequately powered randomised trial. Therefore, at present steroids should be considered only in severe life-threatening refractory hypoxaemia and not after 14 days of ventilation.

\section{Key points}

Acute lung injury (ALI) and acute respiratory distress syndrome (ARDS) remain major causes of morbidity, mortality and healthcare burden in the critically ill patient

The mode of lung injury can be either direct or remote to the lung and is defined as acute onset of severe hypoxaemia and bilateral infiltrates in the absence of left atrial hypertension

A lung protective ventilation and conservative fluid management strategy should be adopted in the management of ALI

High frequency oscillation ventilation and referral for extracorporeal membrane oxygenation (ECMO) should be considered in severe ARDS

To date no pharmacological therapies have shown benefit in large clinical trials

KEY WORDS: acute lung injury, acute respiratory distress syndrome 


\section{The future}

Since delayed goal-directed therapy of sepsis is a risk factor for lung injury, greater clinical benefit may derive from initiating therapy prior to the onset of severe respiratory failure. Thus there is renewed interest in accurate characterisation of high-risk patient populations and identification of patients in the early stage of ALI prior to the need for mechanical ventilation. Clinical trials are underway such as the Beta Agonist Lung Injury Trial Prevention (BALTIPrevention) which is examining the efficacy of the long-acting beta-agonist salmeterol for preventing lung injury in patients at high risk of ALI (eg those undergoing oesophagectomy). ${ }^{19}$

Ongoing research is evaluating the value of many new therapies, including simvastatin, keratinocyte growth factor and mesenchymal/amniotic fluid stem cells. Neuromuscular blocking agents have recently been re-evaluated with favourable results. A recent trial has shown that cisatracurium given for 48 hours early in the course of ARDS with low $V_{t}$ ventilation may improve outcomes without significantly increasing the incidence of muscle weakness. ${ }^{20}$ Further studies are required before these approaches can be adopted in routine practice.

\section{Outcomes}

The advent of lung protective ventilation has resulted in reduced mortality in patients with ALI. Nevertheless, ALI carries an enormous burden in both social and fiscal cost, ${ }^{21,22}$ with mortality rates still around $40 \%$ and significant pulmonary impairment in up to $50 \%$ of survivors. ${ }^{9}$ Debilitating long-term sequelae in survivors include pulmonary, psychological and neurologic impairment ${ }^{23}$ (discussed in more detail in the accompanying article Sequelae and rehabilitation after critical illness (pp $\mathrm{xxx}-\mathrm{xxx})$ ).

\section{Conclusions}

Our understanding of the pathophysiology of ALI has improved dramatically since the first defining reports. Large-scale clinical trials have generated ventilatory strategies which have resulted in reduced mortality. Effective specific drug therapy for ALI has remained elusive despite the establishment of large clinical trials networks. Hopefully emerging therapy to prevent or treat ALI currently under investigation will provide additional strategies to reduce the burden of this devastating disease.

\section{References}

1 Ashbaugh DG, Bigelow DB, Petty TL, Levine BE. Acute respiratory distress in adults. Lancet 1967;2:319-23.

2 Bernard GR, Artigas A, Brigham KL et al. Report of the American-European consensus conference on ARDS: definitions, mechanisms, relevant outcomes and clinical trial coordination. The Consensus Committee. Intensive Care Med 1994;20:225-32.

3 Quartin AA, Campos MA, Maldonado DA et al. Acute lung injury outside of the ICU: incidence in respiratory isolation on a general ward. Chest 2009;135:261-8.

4 Lewandowski K, Lewandowski M. Epidemiology of ARDS. Minerva Anestesiol 2006;72:473-7.

5 Rubenfeld GD, Caldwell E, Peabody E et al. Incidence and outcomes of acute lung injury. N Engl J Med 2005;353: 1685-93.

6 Iscimen R, Cartin-Ceba R, Yilmaz M et al. Risk factors for the development of acute lung injury in patients with septic shock: an observational cohort study. Crit Care Med 2008;36:1518-22.

7 O'Kane CM, McKeown SW, Perkins GD et al. Salbutamol up-regulates matrix metalloproteinase- 9 in the alveolar space in the acute respiratory distress syndrome. Crit Care Med 2009;37:2242-9.

8 Nathani N, Perkins GD, Tunnicliffe W et al. Kerbs von Lungren 6 antigen is a marker of alveolar inflammation but not infection in patients with acute respiratory distress syndrome. Crit Care 2008;12:R12.

9 Ware LB, Matthay MA. The acute respiratory distress syndrome. $\mathrm{N} \mathrm{Engl} \mathrm{J} \mathrm{Med}$ 2000;342:1334-49.

10 Baumann HJ, Kluge S, Balke L et al. Yield and safety of bedside open lung biopsy in mechanically ventilated patients with acute lung injury or acute respiratory distress syndrome. Surgery 2008;143:426-33.

11 Ventilation with lower tidal volumes as compared with traditional tidal volumes for acute lung injury and the acute respiratory distress syndrome. The Acute Respiratory Distress Syndrome Network. N Engl J Med 2000;342:1301-8.

12 National Heart, Lung and Blood Institute Acute Respiratory Distress Syndrome (ARDS) Clinical Trials Network, Wiedemann HP, Wheeler AP, Bernard GR et al. Comparison of two fluid-management strategies in acute lung injury. $N$ Engl J Med 2006;354:2564-75.

13 Sud S, Sud M, Friedrich JO et al. High frequency oscillation in patients with acute lung injury and acute respiratory distress syndrome (ARDS): systematic review and meta-analysis. BMJ 2010;340:c2327.

14 Peek GJ, Mugford M, Tiruvoipati R et al. Efficacy and economic assessment of conventional ventilatory support versus extracorporeal membrane oxygenation for severe adult respiratory failure (CESAR): a multicentre randomised controlled trial. Lancet 2009;374:1351-63.

15 Ketoconazole for early treatment of acute lung injury and acute respiratory distress syndrome: a randomized controlled trial. The ARDS Network. JAMA 2000;283:1995-2002.

16 Steinberg KP, Hudson LD, Goodman RB et al. Efficacy and safety of corticosteroids for persistent acute respiratory distress syndrome. N Engl J Med 2006;354:1671-84.

17 Randomized, placebo-controlled trial of lisofylline for early treatment of acute lung injury and acute respiratory distress syndrome. Crit Care Med 2002;30:1-6.

18 Meduri GU, Golden E, Freire AX et al. Methylprednisolone infusion in early severe ARDS results of a randomized controlled trial, 2007. Chest 2009;136 (5 Suppl):e30.

19 Perkins GD, Park D, Alderson D et al. The Beta Agonist Lung Injury Trial (BALTI) prevention trial protocol. Trials 2011;12:79.

20 Papazian L, Forel JM, Gacouin A et al. Neuromuscular blockers in early acute respiratory distress syndrome. $N$ Engl J Med 2010;363:1107-16.

21 Bellamy PE, Oye RK. Adult respiratory distress syndrome: hospital charges and outcome according to underlying disease. Crit Care Med 1984;12:622-5.

22 Angus DC, Musthafa AA, Clermont G et al. Quality-adjusted survival in the first year after the acute respiratory distress syndrome. Am J Respir Crit Care Med 2001;163:1389-94.

23 Herridge MS, Tansey CM, Matté A et al. Functional disability 5 years after acute respiratory distress syndrome. $N$ Engl J Med 2011;364:1293-304.

\author{
Address for correspondence: $\operatorname{Dr}$ DR \\ Thickett, Centre for Translational \\ Inflammation Research, School of \\ Clinical and Experimental Medicine, \\ University of Birmingham, Edgbaston, \\ Birmingham B15 2TT. \\ Email: d.thickett@bham.ac.uk
}

